\title{
Development of SITU: a survey to measure the impact of outreach activities
}

\author{
Dr Emma J. Vardy, Lecturer in Psychology, Nottingham Trent \\ University, UK \\ Dr Penney Upton, Associate Professor, University of Canberra, \\ Australia
}
Prof. Dominic Upton, Dean of the College of Health and Human Sciences, Charles Darwin University, Australia

\section{Email: emma.vardy@ntu.ac.uk}

\begin{abstract}
The Office for Students' (OfS) aims are clear that it wants to increase robust evidence to understand the impact of outreach activities. There are different mechanisms to collate this evidence which outreach departments can use. To support the collection of robust evidence, this paper outlines the development of Students' Intentions towards University (SITU), a survey that practitioners can use as part of evaluating outreach activities such as ad hoc events or intensive interventions. This paper outlines the four stages that were undertaken to develop SITU to ensure a reliable and valid measure was constructed. At each stage, young people (aged 13 to 18) were consulted to ensure the measure was fit for purpose. The final survey comprises 15 items and is a quick, easy-to-administer survey that practitioners can use confidently. It is proposed that the survey will provide a valid data-collection tool to measure the outcome of outreach activities and the paper will be used as a guide for outreach departments to construct their own measures. Further research is required to test the application of the measure.
\end{abstract}

Key words Widening participation outreach; evaluation; survey design; outreach activities

\section{Introduction}

The evaluation of outreach work is of importance. The Office of Students (OfS, 2019a) has produced guidelines to emphasise the critical role evaluation has to play in addressing the limited amount of high-quality, robust evidence reporting the impact of outreach activities. Knowledge of both effective and ineffective outreach activities is needed due to the financial and time commitment of the programmes. Thus, evaluation needs to become an integral part of outreach work (OfS, 2019a). Evaluation can be qualitative, quantitative or mixed method; this paper outlines the development of a selfreport questionnaire that outreach departments could use to collect what the 
OfS classifies as type 2 evidence, that is, evaluation data that is measuring change. This paper has also included detailed descriptions of each stage to support outreach practitioners to devise their own outcome measures.

Outreach activities can be seen as aiming to change behaviour in three areas: learning, behaviour and reaction. Outreach departments need to show that an outreach activity has had an impact on learning, for example, showing that young people have a better understanding of tuition fees. Harrison and Waller $(2015,2018)$ noted that outreach practitioners felt they were successful in improving knowledge about HE, dispelling negative stereotypes and raising aspirations. Departments then need to track this learning to report whether this impacts on behaviour (e.g. progression to HE); however, this is difficult due to the limited availability of data for longitudinal tracking of young people (Harrison and Waller, 2015). Reaction requires outreach teams to measure students' enjoyment of an outreach activity.

Much of the evaluation work to date has focussed on this latter aspect, enjoyment of an event, rather than measuring a change in intention to progress to HE. A review of outreach evaluations conducted by EKOS Consulting (2007) reported survey items focused on young people's enjoyment of the activity. Surveys did not ask whether or not a person already intended to progress to $\mathrm{HE}$ or if participating in an activity had changed their intentions to do so (EKOS Consulting, 2007). The OfS (2019a) wants evaluation work to report on the outcome that activities are having and also the impact on access to and participation in $\mathrm{HE}$ by targeted groups for widening participation. Thus, there is now much more emphasis on capturing change through valid data-collection tools (OfS, 2019b. However, there are challenges to improving practices: first, resources and, second, the access and quality of data to evaluate outreach activities (Harrison and Waller, 2015).

There is a concern that the focus on evaluation will be a burden for outreach departments (Raven, 2016). This may be due to a number of reasons, with one being that evaluation has, to date, not been a key focus of outreach work. Few departments have an evaluation framework to understand which intervention is - or combination of interventions are - effective (Moore et al., 2013) or whether their overall strategy of outreach work is fit for purpose. Evaluation needs to be embedded into what outreach departments do to understand what activities are effective, for whom and in what context, as well which activities are not effective or need improving (OfS, 2019a). What is required is a reliable way to capture data on outcomes that does not burden the students or interrupt the delivery of an activity. 
Harrison and Waller (2015) surveyed senior managers with a responsibility for widening participation. From the 57 respondents, a large proportion felt confident in the evidence base that underpinned their activities, with questionnaires being the most frequently used method of data collection. However, nearly all respondents wanted to improve their evaluation practices. Respondents acknowledged that for each activity or programme, different evaluation techniques are needed; it is not 'one approach fits all'.

Raven's (2016) evaluation framework offers a systematic way of collecting evaluation data. The evaluation framework outlines how activities can be monitored and evaluated. It considers the short-, medium- and long-term impact of an activity. Building upon on this framework, surveys were mentioned as one way of collecting this data. Unfortunately, no examples were offered to use as part of this framework, which would support practitioners in their evaluation work.

Surveys are one of the main methods of collecting data to understand the impact of outreach activities (Passey and Morris, 2010; Harrison and Waller 2015), as they enable practitioners to gather with ease data from the large number of young people who attend outreach activities. However, many of the surveys currently used to evaluate outreach activities are too flawed to report valid conclusions of effectiveness (Johnston and Paton, 2008). The quality of the surveys used to measure outreach activities is considered to be below acceptable standards. Little is known about how the surveys are constructed, which calls into question the reliability and validity of the measures (Chilosi et al., 2010). Furthermore, the items do not allow for longterm impact or comparison across a number of activities (Doyle and Griffin, 2012; EKOS Consulting, 2007). The poor quality of the surveys to date has subsequently fed into the poor quality of research evidence for outreach activities, resulting in departments being unable to determine the impact and effectiveness of outreach activities (Gorard et al., 2006; Thomas, 2011; Doyle and Griffin, 2012). These sources reporting the limitations of surveys can be considered out of date; however, the situation is still the same. Self-report data is unreliable unless the questionnaire used is well designed (OfS, 2019b). A well-designed questionnaire would address reliability concerns and enable outreach departments to collect data at scale and provide a rich insight into their programmes.

It is thought that practitioners are concerned about how to gather data and report the evidence needed (Raven, 2016). In reporting evaluation findings to build a national picture, a survey that all departments could use would support 
building evidence-based programmes mentioned by the OfS (2019a). It would allow for departments to know the effectiveness of activities, with whom and in what situations. Longitudinal tracking of participants would enable this; however, this takes time, which does not match the objectives of institutions or policy demands (Harrison and Waller, 2018). A survey can provide a snapshot of impact to evidence outreach activities, determine success and build a picture of effectiveness.

This paper outlines the stages taken to develop a survey to use in the evaluation of outreach activities with young people. Young people were the target audience due to much of the outreach activity where the scale was developed being with this group. The survey was designed to address the concern around demonstrating the success of Aimhigher ${ }^{\mathrm{i}}$ activities (Harrison and Waller, 2018). The stages to be outlined were undertaken to ensure that Students' Intentions towards University (SITU) is a reliable and valid measure to evaluate outreach activities. The paper describes each stage in detail to act as a guide for outreach departments to support their own evaluation work. Thus, there are two aims to this paper: one, to share SITU to support the evaluation of outreach activities and, two, to support outreach practitioners in designing valid questionnaires for their own evaluation work.

\section{Survey development: the design}

A carefully planned approach to generate items was used in the initial stage of the survey's development to improve the internal validity. For the construction of SITU, several stages were conducted: generation of an item pool, determination of the measure format, a review by experts of the measure, administration of the items to evaluate and make amendments based on these data, and then piloting (DeVellis, 2003).

Item generation derived from a comprehensive literature review and focus groups with young people and relevant experts in the field (Streiner and Norman, 2008; Onwveglouzie et al., 2010). The focus groups with young people were useful to generate items, inform item phrasing and ensure face and content validity of the survey (i.e. that items measured what they were intended to measure). The words of the young people informed the phrasing of items, and they also were able to provide feedback on the items devised to ensure clarity, relevance and length to enhance the validity of the measure (Onwveglouzie et al., 2010). To addressed a concern from the OfS (2019b) guidance that poorly worded questions result in inaccurate responses. A considerable amount of time was dedicated to the development of the scale 
items to highlight any errors in the early stages of scale development in order to avoid any difficulties later in the process.

A psychometric approach was used to select the final items for the survey. Factor analysis is a statistical method that organises items into factors based on their relationship with each other. A short survey was designed to reduce the burden on participants and motivate respondents (Streiner and Norman, 2008; DeVellis, 1991). To devise valid data-collection tools, outreach departments need to test whether respondents can answer questions accurately. This can be through focus groups with the target audience to test understanding of the items, as well as by piloting the survey. For SITU, several stages were involved in the development, as outlined below in Figure 1 ; each stage will be described in detail so that outreach teams can use this when developing their own data-collection tools to ensure they are valid.

\section{Figure 1: Stages of Scale Development}

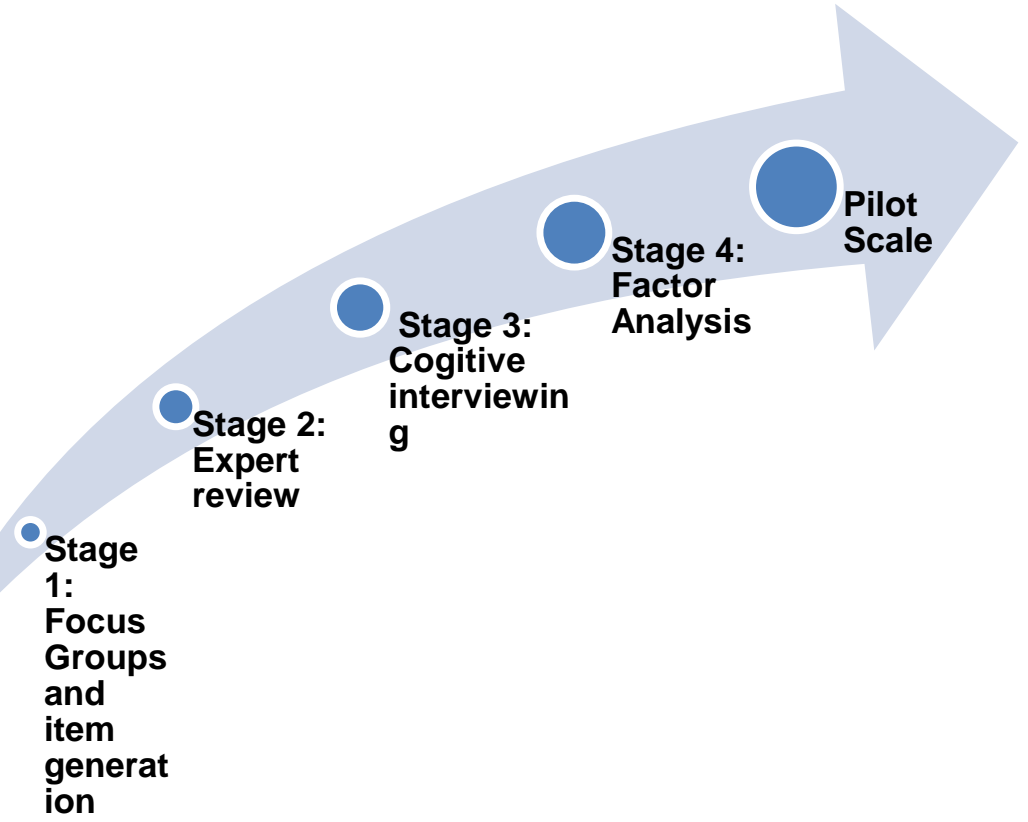

\section{Stage 1: Item generation}

To ensure the survey engaged young people so that they would respond accurately (OfS, 2019b), this stage involved young people in the generation of the questionnaire items. Those who were engaged in outreach activities and attended schools that were targeted for outreach work by Aimhigher were consulted during the first stage. This was to avoid poorly worded items, as this can reduce the usefulness of the measure developed (Worthington and 
Whittaker, 2006). There were three stages to the item generation: literature review, focus groups with young people and expert review.

Following a literature search to inform the focus group prompts, ethical approval was granted for the focus groups. Only those whose parents completed consent forms were included in the groups. A sample of 65 young people (29 female and 36 male) aged 13-18 (school years 9-13) were recruited to nine mixed-sex focus groups to shape the item pool, comment on the clarity of the items and provide suggestions for improvements.

The focus groups explored the young people's expectations of HE and what factors influenced their decisions regarding whether to progress to HE. Prompts around parents and teachers were included, as these factors have a strong influence on intention to progress to HE (Harrison and Waller, 2018). The young people discussed a number of factors that influenced their decisions to progress to HE, which informed the survey items. Factors included: motivation, determination, school, parents, grades and peers. Those factors that appeared most frequently across all of the focus groups informed the survey items.

The first author triangulated the literature search and focus-group data to devise the scale items. They then went back to a small group of the focus group respondents to review the items generated and whether these matched their thoughts. The young people were an integral part of the progress to ensure a robust foundation for the scale.

Once the items had been agreed with the young people, the items were then reviewed by experts in the field to ensure they covered the area of interest and were of relevance (Streiner and Norman, 2008). Consultation was undertaken with 12 selected experts regarding whether the items addressed the intended topic area. The criterion for selection was the experts having researched or been employed in the area of widening participation. Experts represented different perspectives on the matter of widening participation and/or educational progression, with five holding academic posts, two Aimhigher practitioners, two teachers, two Connexions ${ }^{\mathrm{ii}}$ officers and one postgraduate student. Experts were selected from a variety of professions to reflect current understanding of widening participation policy and ensure an array of views were included. The experts commented on the individual items and overall content of the scale. This process drew on expertise to ensure the items generated would be of use to evaluate outreach activities. 
Following the generation of the item pool, items were checked to make sure they were not complex, ambiguous, double-barrelled, leading or contain jargon (Streiner and Norman, 2008. Any ambiguous items were either eliminated or rewritten (Streiner and Norman, 2008). The items generated were checked with a sample of young people, in addition to experts. A number of minor changes were made to the items generated following discussions with the young people involved. For example, using 'university' rather than 'higher education', as it is a more widely used term. Overall, the items were considered to cover the breadth of the topic area, with minimal rewording suggested to enhance quality. To improve the internal validity of the survey, it was important the items were assessed to ensure that respondents found the items easy to answer and to highlight any ambiguous items to either amend or discard (van Teijlingen and Hundley, 2002). To achieve this, cognitive interviewing was used at Stage 2.

\section{Stage 2: Cognitive interviewing}

Cognitive interviewing explores the mental processes respondents use to answer survey items to identify any areas of difficulty when answering questions (Streiner and Norman, 2008). It is a technique that can be used to test whether responses are valid and respondents understand the questions, addressing the areas of concern in the OfS (2019b) guidance to evaluate outreach activities.

Nine young people (six female and three male) aged 13-18 (school years 9-11) were recruited from one target outreach school, all of whom had participated in at least one outreach activity.

Two different approaches for cognitive interviewing can be used; for this project, to improve the richness and quality of the data collected, the two approaches of thinking aloud and verbal prompting were conducted simultaneously (Willis, 2005). Thinking aloud involved the respondent verbalising their thoughts about the question aloud, while the researcher audio recorded the process. The personality of a respondent can impact on the richness of the data collected through the thinking aloud technique, with introverts feeling uncomfortable with the situation (Willis, 2005). Therefore, verbal probing was used also to eliminate any bias from the thinking aloud process. For the verbal probing, the researcher asked at the end of each question certain probes to obtain additional information about the response. Concurrent probing technique was used as the information to reply is fresh in respondents' minds, reducing the possibility of the respondents fabricating an 
explanation (Willis, 1999). In each interview, the respondents were asked to think aloud when responding and after completing an item, then asked the probe question. The following scripted probes, based on Willis (1999) guidelines, were used:

1. Comprehension/interpretation probe: What does the term 'research project' mean to you?

2. Paraphrasing: Respondents were asked to repeat the item in their own words.

3. Recall probe: Can you remember how many family members have attended university?

4. General probes:

a. Why did you choose to answer the item that way?

b. Was that an easy item to answer?

c. I noticed you seemed unsure there, could you tell me what you were thinking.

Informed parental consent was sought before the cognitive interview. Each respondent was interviewed in a quiet room on the school premises. Along with audio recording the interviews, a score sheet was used to document any difficulties immediately. Interviews were scheduled for half an hour. Respondents were informed that the interview was not to collect survey data from them, but rather to test the survey and explore whether there were any items that were difficult to understand, hard to answer or made little sense, reassuring the young people that they could provide their opinions confidently.

At this stage of the scale development, the focus was the wording of the items and checking understanding to provide a valid data-collection tool for outreach activities. Cognitive interviewing was an important stage of the scale construction to detect any errors in the question-answering process and then reword, delete or change the order of items, so that the respondents could complete the survey with ease. For some activities, there may be a lot of participants, for example, masterclasses or campus visits; to ensure the responses gathered via a questionnaire are valid, time should be spent checking item understanding, as the practitioner delivering the session will not have the capacity to support a large number of young people to answer the questions accurately. 
There were few difficulties detected in the respondents' ability to complete the items. Difficulties highlighted through item probing required minimal modifications, including rewording or redefining of what information the item was requesting from respondents. Changes included:

- 'I know what grades are needed to get into university.' The item was considered difficult to answer, as respondents stated that they would only know the answer to this item once they were researching university options in sixth form, so the item was omitted.

- 'I know I will achieve the grades needed to get into university.' The phrasing of the item was considered emotionally loaded, so respondents felt they could not agree, as they did not know whether they would achieve the grades it was hoped they would. The suggestion was then to reword the item to 'I think I will achieve the grades needed to go to university'.

'My parents/carers encourage me to get good grades so I can go to university.' Respondents acknowledged that their parents encourage them to achieve at school, but not for the specific reason of attending university, as it was not an appropriate choice for all. The 'so I can go to university' part of the item was therefore omitted.

The Flesch-Kincaid reliability score for the final scale was 7.8, indicating that the items could be understood by a child aged 12 years old. The response format agreed with the young people was a four-point Likert scale ranging from strongly agree to strongly disagree. When evaluating outreach activities, there is not a lot of time to capture impact, thus it is important young people understand the questionnaire items. This stage can help practitioners to develop valid and reliable questionnaires, addressing limitations of using selfreport data to evidence the outcomes of outreach activity.

\section{Stage 3: Psychometric properties}

This stage of the survey development assessed the psychometric properties of the survey, that is, the validity and reliability of the survey. It is important that data-collection tools used by outreach departments are valid and reliable (OfS, 2019b). To achieve this, the measure must have excellent psychometric properties. Factor analysis is a data-reduction technique that reduces a large number of variables (Field, 2009). At this stage, the focus was on demonstrating the survey was valid, so that any findings reported from the scale could be considered as credible evidence. If outreach departments do 
not have the skill set for such techniques, departments within the university or students could be included in an evaluation team to support questionnaire development.

A sample of 279 students completed the measure from schools that participated in outreach activities facilitated by the Aimhigher department. In total,139 (49.8\%) of the respondents were male and 138 female (49.5\%). The majority of respondents were in year 11 (22.9\%; ages 15-16), then year 9 (22.2\%; ages 13-14), year 10 (21.9\%; ages 14-15), year 7 (19.7\%; ages $11-$ 12 ) and year $8(13.3 \%$; ages $12-13)$. The sample was predominately of white ethnicity (89.6\%) and 9.3\% stated they were entitled to free school meals.

To determine whether a data set is suitable for factor analysis, you need to consider sample size and the strength of the relationship between the items. In terms of sample, the rule of thumb is the larger the sample pool, the better, with a comfortable sample for factor analysis being around 300 participants (Pallant, 2013). The Kaiser-Meyer-Olkin test is used in SPSS ${ }^{\text {iii }}$ to check for sampling adequacy. For this scale, the Kaiser-Meyer-Olkin reported that the sample size was adequate for factor analysis (0.81) (Field, 2009). The second implication to check for is the relationship between items; if variables highly correlate with each other, then factor analysis is not suitable. You should consult Bartlett's test of sphericity ${ }^{\text {iv }}$; this should be significant for factor analysis to be appropriate (Pallant, 2013). For the survey, Bartlett's test of sphericity reported significant $(\mathrm{p}<.001)$, indicting that factor analysis was appropriate. Before running a factor analysis, both of these tables need to be checked to assess the suitability of data collected.

The next stage of factor analysis is factor extraction, which is a technique that reports the smallest number of factors that best represent the interrelationship among the items (Pallant, 2013). There are a number of approaches that can be used; for this scale, principal axis factoring ${ }^{\mathrm{V}}$ was used. To decide the number of factors to retain, there are three techniques that can be consulted. Kaiser's criterion is the most common technique; for this, factors with an eigenvalue of 1.0 are retained. The eigenvalue of factor explains the amount of total variance explained by that factor (Pallant, 2013). For the current scale, two factors reported eigenvalues over Kasier's criterion of one, accounting for $35.9 \%$ of the variance. Another approach to retain factors is the scree test ${ }^{\mathrm{vi}}$; it is recommended that factors that are above the elbow $^{\text {vii }}$ are retained (Pallant, 2013). The scree plot supported retaining two factors for the survey. 
At Stage 3, once the number of factors has been decided, the next step is to interpret these factors. An oblique rotation ${ }^{\text {viii }}$ (direct oblimin) was used alongside researcher judgement to determine the structure of the measure developed. A two-factor scale structure was used; factor one represents the influence of parents, peers and personal intentions held towards HE, and factor two represents the influence school experience has on the intentions young people hold towards HE.

The internal reliability for the 11 items of factor one was .82 and for the four items of factor two, .72. Cronbach's alpha (1951), which reports the reliability of the measure comprised of 15 items, was .84 , exceeding the accepted criteria of .70 (Streiner and Norman, 2008). The measure established good internal reliability.

At this stage of the scale development, we used exploratory factor analysis, which is used in the early stages of scale development to explore the relationship between the variables. The factor analysis was used to support the researchers' decisions on which items fitted the scale. Following the factor analysis, the scale comprised 15 items with a two-factor structure.

Test-retest reliability demonstrates whether a measure is consistent over time. This was assessed to account for any response variations (Streiner and Norman, 2008). For test-retest reliability, the measure was administered twice, with a time lapse of two weeks (Streiner and Norman, 2008). This is the optimum time between administrations, as with a shorter period, recall effects may bias findings, while any longer may result in systematic changes in respondent beliefs, knowledge or attitudes, thereby influencing findings (Nunnally, 1978). These two sets of scores were then correlated; a reported correlation greater than .5 establishes the external reliability of the measure (Streiner and Norman, 2008).

A sample of 95 students were recruited, 47 male (49.5\%) and 48 female $(50.5 \%)$, who completed the scale at two time points. The majority of the respondents were year 9 students $(30.5 \%)$, followed by year 7 (27.4\%), year $8(23.2 \%)$ and year $10(18.9 \%)$. The sample was predominately of white ethnicity $(87.4 \%)$. Five percent stated they were entitled to free school meals.

A correlation between time one total score and time two total score on the measure was conducted. The results indicated the measure to be consistent over time, indicating that the underlying process is unlikely to fluctuate over a short period, $r=.748, \mathrm{p}<.01$. One type of evidence the OfS (2019a) mentions is empirical enquiry, measuring change pre- and post-outreach 
activity. A scale that does not change over a short period of time would enable practitioners to report that any changes from a long activity could be as a result of the programme, rather than other confounding variables.

Test-retest reliability was undertaken to assess the stability of the measure. Typically, for scales measuring attitude, test-retest reliability is not conducted (Streiner and Norman, 2008). However, for this study it was considered appropriate to explore whether the scale can be used to measure a change in attitude from taking part in outreach activities. Results reported that the measure was stable over time, indicating that the underlying process was unlikely to fluctuate over a short period (Streiner and Norman, 2008).

\section{Pilot of Students' Intentions Towards University (SITU)}

To assess the suitable of the scale, a pilot study was conducted. The scale was used to recruit young people to an outreach activity. Respondents to Harrison and Waller's (2015) survey reported mixed levels of confidence in schools about nominating the right individuals for outreach activities. Thus, this is one way outreach departments could use the measure: to target the right young people for outreach activities, using the scale alongside teacher judgement.

A total of 87 young people from year 9 completed the measure, 31 male and 56 female. Permission was sought from the young people's parents to participate in the pilot study.

The mean scores for the pilot of SITU show a stark difference between the potential outreach group and the control group, with those in the control group possessing a more positive attitude towards HE, see Table 1. It is important to note that the scores were widely dispersed from the mean as indicated by the high standard deviation scores.

\section{Table 1: SITU pilot mean scores}

\begin{tabular}{|l|l|l|}
\hline & $\begin{array}{l}\text { Intervention } \\
\text { group }\end{array}$ & $\begin{array}{l}\text { Control } \\
\text { group }\end{array}$ \\
\hline $\begin{array}{l}\text { Mean and standard deviation of the } \\
\text { intention measure to HE }\end{array}$ & $36.55(28.2)$ & $54.11(19.6)$ \\
\hline
\end{tabular}

An independent samples t-test ${ }^{\mathrm{ix}}$ was conducted to compare the scores on SITU for the two groups; a significant different in scores, $t(68)=3.314 p$ > .001 was reported. Reviewing the descriptive statistics, the significant 
difference relates to the control group reporting a more positive attitude towards HE than the potential outreach group. This suggests the right learners had been recruited for outreach work. The measure has the potential to be used to target the correct learners for outreach activities. Using the survey in this way would address concerns of the reliability and validity of the data used to select the right learners for outreach activities (Harrison and Waller, 2015) Further pilot work is needed.

\section{Conclusion}

This paper has discussed the steps taken to develop a self-report measure that outreach departments could use to evaluate their activities. The OfS (2019awants evidence-led approaches in outreach work, with evaluation informing decisions being made. Outreach departments are confident in the evidence base that underpins their activities; however, they want to improve their evaluation practices (Harrison and Waller, 2015). Valid data-collection tools are needed that departments can use. The four stages taken in this paper were used to devise a valid and reliable measure and can be applied to the development of new measures for outreach activity. The final survey is quick and easy to administer, with the aim to support practitioners to evaluate their outreach activities. Furthermore, having a scale that all departments can use will help to build a national picture of the impact activities are having.

The Students' Intentions towards University survey comprises 15 items with a two-factor structure. Factor one includes items demonstrating the combination of parental and peer influence associated with intentions held towards HE. Factor two represents the influence school experience has on the intentions young people hold towards HE. Examination of the items retained in the final measure shows that no single factor influences young peoples' educational choices: a combination of internal and external factors can explain an intention held towards engaging with HE (Moogan, 2011; AbbottChapman, 2011).

An examination of items loading onto factor one supports research that suggests parents are significant influencers on educational choices (Herlickson et al., 2009; See et al., 2011; Kirk et al., 2011;). Items measuring parental encouragement and involvement were reported to be associated with personal decisions measured by career aspirations and motivation levels to learn. Items measuring school experience loaded onto factor two, which supports the idea that parents are a strong push factor in encouraging educational engagement, but schools and teachers may influence whether a 
young person stays in education, so these are a pull factor (See et al., 2011). The factor loading also supports Foskett et al.'s (2008) research that school experience is shaped by various factors, including teachers, ethos and career advice and guidance. These factors together can contribute to a young person's school experience, which subsequently influences post-compulsory education progression.

The scale demonstrated good reliability and validity. This is of importance, as the measure was developed to be used to evaluate outreach initiatives. The intended application of the measure is to evaluate outreach programmes with a pre- and post-test design; therefore, measuring stability was of importance. This finding supports the aim that the measure is suitable for the evaluation of outreach activities.

The approach taken in this paper can be applied to develop data-collection tools for outreach programmes. It is a time-consuming process, but results in a survey that can contribute to understanding what works in outreach work. It is important to share knowledge of what works and what does not in order to improve what support is offered to young people. Self-report data can be unreliable if the questions are confusing for respondents, poorly worded and/or do not engage respondents (OfS, 2019b). Engaging the target audience at the start of questionnaire design overcomes some limitations, as you can check whether respondents understand the items and whether the responses are valid. For activities where time is restricted, self-report measures can offer rich insight from a large number of participants to inform on the changes an activity has had, if the questionnaire developed is valid. It is hoped this paper has produced a guide that practitioners can use for their own questionnaire development. Of course, even with a sound questionnaire, there are limitations to just relying on self-report data; thus, where possible, questionnaire data should be triangulated with additional data.

The survey has acceptable measurement properties, but the limitations should be considered. The scale does need to be piloted by departments to evaluate outreach activities. The reliability and validity of the measure was established at this stage; however, it is recommended that further work should be carried out to establish both construct and discriminant validity. Establishing discriminant validity is important, as a potential use for the measure is to discriminate between young people with an intention to attend $\mathrm{HE}$ and those who have no intention, in order to assist in targeting outreach activities. To ascertain this, the scale would need to be completed by a large group of young people and a comparison of scores be conducted. A low score 
on the measure would equate to no intention to attend HE compared to a higher score. Further development of the measure is an avenue for future research.

The final survey comprises 15 items and is a quick, easy-to-administer survey that practitioners can use confidently. It is proposed that the survey will provide a valid data-collection tool to measure the impact of outreach activities. It is the aim of this paper that the approach outlined and the scale itself will strengthen evaluation work within outreach work. Further research is required to test the application of the measure.

\footnotetext{
${ }^{\mathrm{i}}$ Aimhigher was a series of initiatives aimed at widening participation in UK higher education, particularly among students from non-traditional backgrounds, minority groups and people with disabilities.

ii The Connexions Service in England was part of a government strategy to reduce social exclusion among young people.

iii SPSS Statistics is a software package used for statistical analysis.

iv A test to evaluate whether the sphericity assumption has been violated. The sphericity assumption is an assumption about the structure of the covariance matrix in a repeated measures design.

${ }^{\mathrm{v}}$ Is the most widely used method for exploratory factor analysis to decide the number of factors to retain. .

vii The elbow is where the eigenvalues seem to level off.

viii A rotation method used in factor analysis that allows the underlying factors to be correlated.

${ }^{\text {ix }}$ A test used to see whether two means collected from independent samples differ significantly by using the t-statistic.
} 


\section{References}

Abbott-Chapman, J. (2011) 'Making the most of the mosaic: facilitating postschool transitions to higher education of disadvantaged students', Australian Educational Researcher, 38, 1: 57-71.

Chilosi, D., Noble, M., Broadhead, P. and Wilkinson, M. (2010) 'Measuring the effect of Aimhigher on schooling attainment and higher education applications and entries', Journal of Further and Higher Education, 34, 1: 110.

Cronbach, L. J. (1951) 'Coefficient alpha and the internal structure of tests', Psychometrika, 16, 3: 297-334.

DeVellis, R. F. (1991) Scale Development: Theory and Applications, Newbury Park, CA: Sage Publications Inc.

DeVellis, R. F. (2003) Scale Development, 2nd edn, Thousand Oaks, CA: Sage.

Doyle, M. and Griffin, M. (2012) 'Raised aspirations and attainment? A review of the impact of Aimhigher (2004-2011) on widening participation in higher education in England', London Review of Education, 10, 1: 105-115.

EKOS Consulting (2007) Aimhigher Area Studies: Final report to HEFCE by EKOS Consulting, Bristol: Higher Education Funding Council for England (HEFCE).

Field, A. (2009) Discovering Statistics using SPSS, 3rd edn, London: Sage.

Foskett, N., Dyke, M. and Maringe, F. (2008) 'The influence of the school in the decision to participate in learning post-16', British Educational Research Journal, 34, 1: 37-61.

Gorard, S., Smith, E., May, H., Thomas, L., Adnett, N. and Slack, K. (2006) Review of Widening Participation Research: Addressing the Barriers to Participation in Higher Education, Bristol: HEFCE.

Harrison, N. and Waller, R. (2015) The evaluation of widening participation activities in higher education: A survey of institutional leaders in England, Bristol: University of the West of England.

Harrison, N. and Waller, R. (2018) 'Challenging discourses of aspiration: The role of expectations and attainment in access to higher education', British Educational Research Journal, 44, 5: 914-938.

Herlickson, A. B., Wettersten, K. B., Herrick, C. G., Kim, G. Y., Hunter, P. J., Guilmino, A. and Rudolph, S. E. (2009) 'Initial Development and 
Psychometric Properties of the Adolescent Perceptions of Parental ProEducational Attitudes and Behaviours Scale', Measurement and Evaluation in Counselling and Development, 41, 4: 194-209.

Johnston, R. and Paton, K. (2008) 'Chalk and cheese? Evaluating the impact of Aimhigher in six Southampton schools', Participation Research Group seminar, University of Southampton, 8 July 2008.

Kirk, C. M., Lewis-Moss, R. K., Nilsen, C. and Colvin, D. Q. (2011) 'The role of parental expectations on adolescent educational aspirations', Educational Studies, 37, 1: 89-99.

Moogan, Y. J. (2011) 'An analysis of school pupils' (with low social economic status) perceptions of university, regarding programmes of study', Educational Studies, 37, 1: 1-14.

Moore, J., Sanders, J. and Higham, L. (2013) Literature Review of Research into Widening Participation to Higher Education, Bristol: HEFCE.

Nunnally, J. (1978) Psychometric Theory, New York, NY: McGraw-Hill.

Office for Students (OfS) (2019a) 'Access and participation standards of evidence'. [Online]. Available at https://www.officeforstudents.org.uk/media/6971cf8f985b-4c67-8ee2-4c99e53c4ea2/access-and-participation-standards-ofevidence.pdf (accessed: 6 July 2020).

Office for Students (OfS) (2019b) 'Using standards of evidence to evaluation impact of outreach'. [Online]. Available at https://www.officeforstudents.org.uk/media/f2424bc6-38d5-446c-881ef4f54b73c2bc/using-standards-of-evidence-to-evaluate-impact-ofoutreach.pdf (accessed: 6 July 2020).

Onwveglouzie, A. J., Bustamante, R. M. and Nelson, J. A. (2010) 'Mixed research as a tool for developing quantitative instruments', Journal of Mixed Methods Research, 4, 1: 56-78.

Pallant, J. (2013) SPSS Survival Manual, 5th edn, Maidenhead: Open University Press.

Passey, R. and Morris, M. (2010) Evaluation of Aimhigher: learner attainment and progression, Slough: National Foundation for Educational Research.

Raven, N. (2016) 'Making evidence work: a framework for monitoring, tracking and evaluating widening participation activity across the student lifecycle', Research in Post-Compulsory Education, 21, 4: 360-375.

See, B. H., Torgerson, C., Ainsworth, H., Gorard, S., Low, G. and Wright, K. (2011) 'The factors that promote high post-16 participation of some ethic 
minority groups in England: a systematic review of the UK-based literature', Research in Post Compulsory Education, 16, 1: 85-100.

Streiner, D. L. and Norman, G. R. (2008) Health Measurement Scales, a practical guide to their development and use, $4^{\text {th }}$ edn, Oxford: Oxford University Press.

Thomas, L. (2011) 'Do Pre-entry Interventions such as 'Aimhigher' Impact on Student Retention and Success? A review of the Literature', Higher Education Quarterly, 65, 3: 230-250.

van Teijlingen, E. and Hundley, V. (2002) 'The importance of pilot studies', Social Research Update, 35: 1-4.

Willis, G. B. (1999) 'Cognitive interviewing: A "How To" guide', 1999 Meeting of the American Statistical Association, Research Triangle Park, NC: Research Triangle Institute. Available at https://www.hkr.se/contentassets/9ed7b1b3997e4bf4baa8d4eceed5cd87/gordo nwillis.pdf (accessed: 6 July 2020).

Willis, G. B. (2005) Cognitive Interviewing: A Tool for Improving Questionnaire Design, Thousand Oaks, CA: Sage Publications.

Worthington, R. L. and Whittaker, T. A. (2006) 'Scale Development Research: A Content Analysis and Recommendations for Best Practices', The Counselling Psychologist, 34, 6: 806-838. 


\section{Appendix 1: SITU questionnaire}

\begin{tabular}{|c|c|c|c|c|}
\hline & Strongly agree & Agree & Disagree & $\begin{array}{l}\text { Strongly } \\
\text { disagree }\end{array}$ \\
\hline $\begin{array}{l}\text { 1. I see university as part of } \\
\text { my future. }\end{array}$ & & & & \\
\hline $\begin{array}{l}\text { 2. Once I have finished } \\
\text { compulsory schooling, I } \\
\text { would rather get a full- } \\
\text { time job than go to } \\
\text { university. }\end{array}$ & & & & \\
\hline $\begin{array}{l}\text { 3. I want to go to } \\
\text { university, as it will } \\
\text { improve my chances of } \\
\text { getting a good job. }\end{array}$ & & & & \\
\hline $\begin{array}{l}\text { 4. I think I will achieve the } \\
\text { grades needed to go to } \\
\text { university. }\end{array}$ & & & & \\
\hline 5. I am motivated to learn. & & & & \\
\hline $\begin{array}{l}\text { 6. My parents/carers } \\
\text { encourage me to aim for } \\
\text { university. }\end{array}$ & & & & \\
\hline $\begin{array}{l}\text { 7. My parents/carers would } \\
\text { support my decision to } \\
\text { go to university. }\end{array}$ & & & & \\
\hline $\begin{array}{l}\text { 8. } \\
\text { My parents/carers } \\
\text { encourage me to get } \\
\text { good grades. }\end{array}$ & & & & \\
\hline
\end{tabular}




\begin{tabular}{|l|l|l|l|l|}
\hline $\begin{array}{l}\text { 9. I regularly discuss school } \\
\text { and schoolwork with my } \\
\text { parents/carers. }\end{array}$ & & & & \\
\hline $\begin{array}{l}\text { 10. My friends are thinking } \\
\text { about going to } \\
\text { university. }\end{array}$ & & & & \\
\hline $\begin{array}{l}\text { 11. My friends encourage } \\
\text { me to aim for university. }\end{array}$ & & & & \\
\hline $\begin{array}{l}\text { 12. My teachers encourage } \\
\text { me to achieve good } \\
\text { grades. }\end{array}$ & & & & \\
\hline $\begin{array}{l}\text { 13. My teachers encourage } \\
\text { me to aim for university. }\end{array}$ & & & & \\
\hline $\begin{array}{l}\text { 14. The careers advice at my } \\
\text { school promotes } \\
\text { progression to university. }\end{array}$ & & & & \\
\hline $\begin{array}{l}\text { 15. My school promotes } \\
\text { achievement and further } \\
\text { education. }\end{array}$ & & & & \\
\hline
\end{tabular}

